\begin{tabular}{lcl}
\hline Bentham OPEN & The Open Rheumatology Journal & $\begin{array}{c}\text { The Open } \\
\text { Rheumatology } \\
\text { lournal }\end{array}$ \\
\hline CrossMark & Content list available at: www.benthamopen.com/TORJ/ & DOI: $10.2174 / 1874312901610010109$ \\
\hline
\end{tabular}

RESEARCH ARTICLE

\title{
Fibromyalgia Outcomes Over Time: Results from a Prospective Observational Study in the United States
}

Caroline P. Schaefer ${ }^{1}$, Edgar H. Adams ${ }^{1}$, Margarita Udall ${ }^{2}$, Elizabeth T. Masters ${ }^{2}$, Rachael M. Mann $^{3}$, Shoshana R. Daniel ${ }^{4}$, Heather J. McElroy ${ }^{5}$, Joseph C. Cappelleri ${ }^{6}$, Andrew G. Clair ${ }^{2}$, Markay Hopps $^{2, *}$, Roland Staud ${ }^{7}$, Philip Mease ${ }^{8}$ and Stuart L. Silverman ${ }^{9}$

${ }^{I}$ Covance Market Access Services Inc., Gaithersburg, MD, USA

${ }^{2}$ Pfizer Inc., New York, NY, USA

${ }^{3}$ Covance Market Access Services Inc., San Diego, CA, USA

${ }^{4}$ Covance Market Access Services Inc., Conshohocken, PA, USA

${ }^{5}$ Covance (Asia) Pte Ltd., Singapore

${ }^{6}$ Pfizer Inc., Groton, CT, USA

${ }^{7}$ University of Florida, Gainesville, FL, USA

${ }^{8}$ Swedish Medical Center and University of Washington, Seattle, WA, USA

${ }^{9}$ Cedars-Sinai Medical Center, Los Angeles, CA, USA

Received: June 29, 2016

Revised: November 21, 2016

Accepted: November 21, 2016

\section{Abstract:}

Background:

Longitudinal research on outcomes of patients with fibromyalgia is limited.

objective:

To assess clinician and patient-reported outcomes over time among fibromyalgia patients.

Methods:

At enrollment (Baseline) and follow-up (approximately 2 years later), consented patients were screened for chronic widespread pain (CWP), attended a physician site visit to determine fibromyalgia status, and completed an online questionnaire assessing pain, sleep, function, health status, productivity, medications, and healthcare resource use.

\section{Results:}

Seventy-six fibromyalgia patients participated at both time points (at Baseline: $86.8 \%$ white, $89.5 \%$ female, mean age 50.9 years, and mean duration of fibromyalgia 4.1 years). Mean number of tender points at each physician visit was 14.1 and 13.5 , respectively; 11 patients no longer screened positive for CWP at follow-up. A majority reported medication use for pain $(59.2 \%$ at Baseline, $62.0 \%$ at Follow-up). The most common medication classes were opioids (32.4\%), SSRIs (16.9\%), and tramadol (14.1\%) at Follow-up. Significant mean changes over time were observed for fibromyalgia symptoms (modified American College of Rheumatology 2010 criteria: 18.4 to $16.9 ; P=0.004$ ), pain interference with function (Brief Pain Inventory-Short Form: 5.9 to 5.3; $P=0.013$ ), and sleep (Medical Outcomes Study-Sleep Scale: 58.3 to $52.7 ; P=0.004)$. Patients achieving $\geq 2$ point improvement in pain (14.5\%) experienced greater changes in pain interference with function $(6.8$ to $3.4 ; P=0.001)$ and sleep $(62.4$ to $51.0 ; P=0.061)$.

\section{Conclusion:}

Fibromyalgia patients reported high levels of burden at both time points, with few significant changes observed over time. Outcomes were variable among patients over time and were better among those with greater pain improvement.

* Address correspondence to this author at the Pfizer Inc, 235 East $42^{\text {nd }}$ Street, New York, NY 10017, USA; Tel: 212-733-0717; E-mail: Markay.Hopps@pfizer.com 
Keywords: Burden of illness, Chronic widespread pain, Clinician-reported outcomes, Fibromyalgia, Health resource use, Outcome assessment, Patient-reported outcomes, Quality of life, Treatment patterns.

\section{INTRODUCTION}

Fibromyalgia is a chronic illness with primary symptoms including widespread musculoskeletal pain, as well as stiffness, sleep disturbance, and fatigue. Headache, irritable bowel and bladder, anxiety, and depression are also commonly reported comorbidities [1 - 3]. Fibromyalgia generally presents in middle age [1] and most commonly affects women; estimates of fibromyalgia prevalence range from $0.66 \%$ in Denmark (females and males) [4] to $10.5 \%$ in Norway (females only) [5], with a recent study estimating prevalence to be $6.4 \%$ in the United States (US; females and males) [6]. Previous cross-sectional research has shown that fibromyalgia places a substantial burden on patients with respect to symptoms, loss of function and productivity, and decreased health-related quality of life [2, 7 - 13]. Fibromyalgia is also associated with burden on payers and employers with respect to healthcare resource use, lost productivity, and associated costs [2, 12 - 16].

Longitudinal research on outcomes of patients with fibromyalgia is limited; some previous studies have suggested that patients rarely achieve remission from fibromyalgia, although a portion may experience improvement or waxing and waning in symptoms over time [17 - 24]. One study on established fibromyalgia patients (median disease duration at first assessment was 7.8 years) found that functional disability worsened over the 7-year study period, while measures of pain, global severity, fatigue, sleep disturbance, anxiety, depression, and health status remained unchanged and patient satisfaction with health improved [24]. A study conducted in the US reported that two-thirds of the fibromyalgia sample indicated that their symptoms were a little to a lot better, $10 \%$ reported no change, and a quarter of the sample reported that they were a little to a lot worse at the 10-year interview than when they were first diagnosed [18]. A study conducted in Britain found that $26 \%$ of the fibromyalgia sample reported that symptoms were better, and $60 \%$ reported that symptoms were worse at a mean of 4 years after their initial diagnosis [20]. Previous studies have also reported that a portion $(20 \%-44 \%)$ of diagnosed patients no longer met the study definition of fibromyalgia years after diagnosis [17, $22,23]$.

Given the paucity of published US studies on outcomes among patients with fibromyalgia over time, as well as the variation in reported results, this study followed fibromyalgia patients for approximately 2 years to assess clinician and patient-reported outcomes over time.

\section{MATERIALS AND METHODOLOGY}

This analysis was based on a multiyear observational cohort study with 2 assessments [25]. Patients with fibromyalgia who completed both Baseline and Follow-up assessments were included in this analysis (Fig. 1). Detailed study methods and findings from the Baseline assessment have been published previously [26]. Briefly, at Baseline, a sample of fibromyalgia patients was identified using a large opt-in online panel maintained by Toluna [27]. Patients were identified based on both their responses to a screening survey for CWP (bilateral pain, above/below waist lasting $\geq$ 1 week in the past 3 months), according to the 4 pain questions of the London Fibromyalgia Epidemiology Study Screening Questionnaire (LFESSQ-4; Table 1) [28], and a site visit for physician evaluation of fibromyalgia. During the site visit, physicians completed a tender point exam [29] and blood pressure cuff exam [30], and patients completed the EuroQol 5 dimensions (EQ-5D; Table 1) [31]. Physicians at the study sites had completed FM diagnostic training and reported treating at least $10 \mathrm{FM}$ patients on average each month in their practice. Physicians relied on their clinical impression of the subject, following the assessment, to establish a FM diagnosis. Physicians or site coordinators entered the collected data into an online clinical case report form for each patient. All patients were aged 18 years or older and provided informed consent (in English or Spanish).

Following the site visit, patients completed an online questionnaire that incorporated several validated patientreported outcome (PRO) instruments: Brief Pain Inventory-Short Form (BPI-SF) [32], modified (self-report) American College of Rheumatology (ACR 2010) Criteria [33], Fibromyalgia Impact Questionnaire-revised (FIQ-R) [34], Medical Outcomes Study Sleep Scale (MOS-SS) [35], 12-Item Short-Form Health Survey, version 2 (SF-12) [36], and Work Productivity and Activity Impairment (WPAI) Questionnaire [37]. Details about the items and content of each of these instruments can be found in Table 1. The questionnaire also included questions about comorbidities, clinical characteristics, symptoms (e.g., average pain over the past 7 days), productivity, healthcare resource use, and socioeconomic information. The collected healthcare resource use data included healthcare provider visits, emergency room visits, hospitalizations, prescription medications, physical treatments, nonprescription medications, and herbs, 
vitamins, or other pain supplements the patients were prescribed and/or used for their pain in the past 3 months.

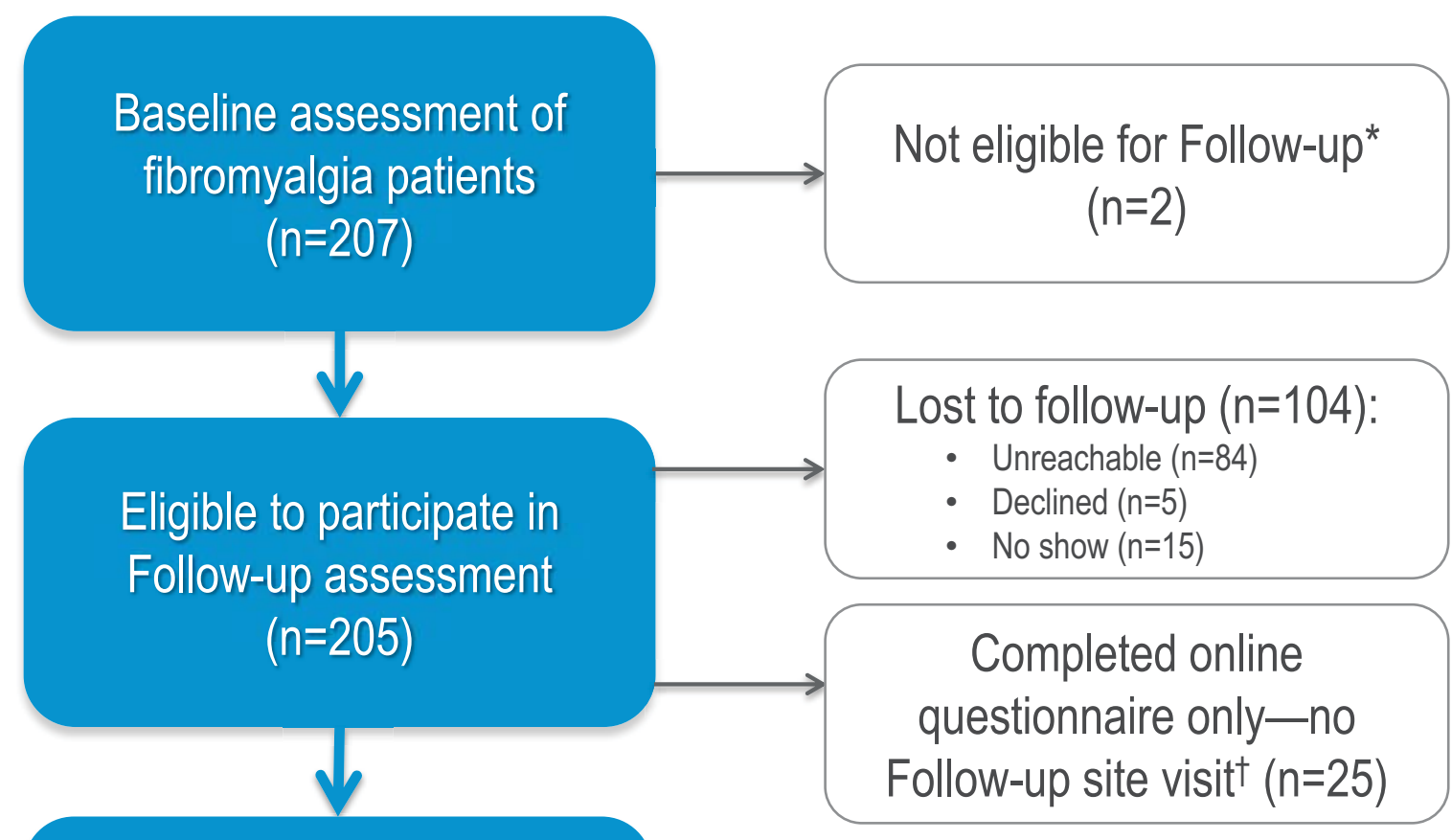

Attended Follow-up site visit ( $n=76 ; 71$ completed online questionnaire at Follow-up)

Fig. (1). Study flow diagram.

"Due to lack of valid e-mail address or Baseline site closure, 2 patients were not eligible to participate in Follow-up.

${ }^{\dagger}$ Patients who were unable to attend the site visit at Follow-up were invited to complete the online questionnaire only; however, given the patients' fibromyalgia status/diagnosis was unknown at Follow-up, these patients were excluded from this analysis.

Table 1. Patient-reported outcome measures.

\begin{tabular}{|c|c|}
\hline Patient-Reported Outcome Measure & Description \\
\hline $\begin{array}{l}\text { 12-item Short-Form Health Survey, } \\
\text { version } 2 \text { (SF-12) }\end{array}$ & $\begin{array}{l}\text { A 12-item measure of health status with } 8 \text { domains (physical functioning, role physical, bodily pain, } \\
\text { general health, vitality, social functioning, role emotional, mental health) and Physical and Mental } \\
\text { Component Summary scores ( } 0 \text { to } 100 \text { scale, higher scores indicate better outcomes) [36] }\end{array}$ \\
\hline $\begin{array}{l}\text { Brief Pain Inventory-Short Form (BPI- } \\
\text { SF) }\end{array}$ & $\begin{array}{l}\text { An 11-item measure of pain severity (Pain Severity Index } 4 \text { items: worst, least, average, current; } 0 \text { to } 10 \\
\text { scale, higher scores indicate more severe pain) and pain interference with function (Pain Interference } \\
\text { Index } 7 \text { items: general activity, mood, walking ability, normal work, relations with other people, sleep, } \\
\text { enjoyment of life; } 0 \text { to } 10 \text { scale, higher scores indicate more interference) [32] }\end{array}$ \\
\hline EuroQol 5 dimensions, 3 levels (EQ-5D) & $\begin{array}{l}\text { A 5-item measure of general health status that assesses mobility, self-care, performance of usual activities, } \\
\text { pain or discomfort, and anxiety or depression. Using the United States-based scoring, the health state } \\
\text { utility is scored on a }-0.11 \text { to } 1.00 \text { scale (higher scores indicate better health status) [31] }\end{array}$ \\
\hline $\begin{array}{l}\text { Fibromyalgia Impact Questionnaire- } \\
\text { revised } \\
\text { (FIQ-R) }\end{array}$ & $\begin{array}{l}\text { A } 21 \text {-item measure of function, overall impact of fibromyalgia, and intensity of symptoms over the past } 7 \\
\text { days. Overall Score based on } 0 \text { to } 100 \text { scale, function on } 0 \text { to } 90 \text { scale, overall impact on } 0 \text { to } 20 \text { scale, and } \\
\text { symptom intensity on } 0 \text { to } 100 \text { scale (higher scores indicate greater impact of fibromyalgia) [34] } \\
\text { Note: at Follow-up this measure was administered to patients who were re-diagnosed with fibromyalgia } \\
\text { by the physician at the Follow-up site visit. }\end{array}$ \\
\hline $\begin{array}{l}\text { London Fibromyalgia Epidemiology } \\
\text { Study Screening Questionnaire } \\
\text { (LFESSQ) }\end{array}$ & $\begin{array}{l}\text { A 6-item screening tool to assess the presence of chronic widespread pain. Patients screened positive } \\
\text { based on responses to the } 4 \text { pain items (LFESSQ-4) indicating bilateral pain, above and below the waist, } \\
\text { lasting at least } 1 \text { week in the past } 3 \text { months [28] }\end{array}$ \\
\hline $\begin{array}{l}\text { Medical Outcomes Study Sleep Scale } \\
\text { (MOS-SS) }\end{array}$ & $\begin{array}{l}\text { A } 12 \text {-item measure of sleep outcomes that includes } 6 \text { dimensions (sleep disturbance, snoring, shortness of } \\
\text { breath, sleep adequacy, sleep somnolence, sleep quantity). Nine items make up the Overall Sleep } \\
\text { Problems Index; } 0 \text { to } 100 \text { scale, higher scores indicate more sleep problems except for sleep adequacy and } \\
\text { sleep quantity items, where higher scores indicate better sleep outcomes) [35] }\end{array}$ \\
\hline
\end{tabular}


(Table $\square$ ) contd.....

\begin{tabular}{|l|l|}
\hline Patient-Reported Outcome Measure & \multicolumn{1}{c|}{ Description } \\
\hline $\begin{array}{l}\text { Modified (self-report) American College } \\
\text { of Rheumatology 2010 Criteria (ACR } \\
2010)\end{array}$ & $\begin{array}{l}\text { A 3-item measure of pain locations and symptoms; 0 to 31 scale (higher scores indicate worse outcomes) } \\
\text { comprised of the widespread pain index (0 to 19 scale) and symptom severity (0 to 12 scale) subscales } \\
{[33]}\end{array}$ \\
\hline $\begin{array}{l}\text { Work Productivity and Activity } \\
\text { Impairment (WPAI) Questionnaire }\end{array}$ & $\begin{array}{l}\text { A 6-item measure used to quantify Overall Work Impairment, comprised of absenteeism and } \\
\text { presenteeism, and Activity Impairment with scores expressed as impairment percentages (higher scores } \\
\text { indicate more productivity loss and greater impairment) [37] }\end{array}$ \\
\hline
\end{tabular}

All fibromyalgia patients who completed the Baseline assessment were eligible to participate at Follow-up approximately 2 years later, with the exception of patients whose e-mail address was no longer available or patients whose study site was closed or did not participate at Follow-up $(\mathrm{n}=2)$. Eligible patients received an e-mail invitation to participate in the Follow-up assessments. If a response was not received after 5 attempts, patients were then called by study sites ( 3 call attempts, each on separate days at different times). Twenty geographically diverse sites participated (5 West, 5 Midwest, 5 South, 5 Northeast) at Baseline, and 17 (5 West, 4 Midwest, 4 South, 4 Northeast) of these sites also participated at Follow-up; 3 sites were unable to participate at Follow-up. Physicians who participated at both Baseline and Follow-up included 9 rheumatologists, 2 pain specialists, and 6 primary care physicians. At Follow-up, patients who provided consent were reassessed for fibromyalgia at the same study site and again completed the set of validated PRO measures administered at Baseline in the online patient questionnaire.* The EQ-5D and LFESSQ were completed on site and entered on the online case report form at Follow-up.

This observational study received Institutional Review Board approval from Quorum Review IRB, Seattle, Washington and Western Institutional Review Board, Olympia, Washington.

\section{ANALYSIS METHODS}

The analyses examined within-group changes over time for fibromyalgia patients from Baseline to Follow-up. Standard descriptive statistics were calculated at both assessments for demographic and clinical characteristics, medications, clinical outcomes, and PROs. To evaluate changes between Baseline to Follow-up, continuous or nearcontinuous outcomes were compared with a paired t-test. Only subjects with both data at Baseline and Follow-up are included in the mean change assessments. Generalized McNemar's test for homogeneity was used for comparisons of categorical outcomes of the same patient between Baseline and Follow-up [38]. Statistical significance was assessed at the 0.05 significance level.

A pain improvement subgroup analysis was conducted on patients who showed at least a 2.0-point improvement between Baseline and Follow-up in average pain severity ( 0 to 10 point scale) over the past 7 days [39 - 41]. Baseline and Follow-up descriptive statistics were used to summarize characteristics of patients achieving/not achieving this 2.0point improvement.

The data were analyzed using SAS version 9.3 of the SAS $^{\circledR}$ software package (SAS Institute, Cary, North Carolina).

\section{RESULTS}

A total of 76 fibromyalgia patients completed the Baseline and Follow-up site visits for physician evaluation of fibromyalgia; 71 (93.4\%) of those patients also completed the online patient questionnaire at Follow-up (Fig. 1). Demographic and clinical characteristics of the fibromyalgia group are presented in Table $\mathbf{2}$. The majority was female and non-Hispanic. The mean age at Baseline was 50.9 years and 53.2 years at Follow-up. Less than a third of patients were employed for pay at each assessment. The majority of patients was obese (body mass index $[\mathrm{BMI}] \geq 30 \mathrm{~kg} / \mathrm{m}^{2}$ ) [42] at both assessments. Mean time since fibromyalgia diagnosis at Baseline and Follow-up was 4.1 years and 6.2 years, respectively.

Comorbidities, such as arthritis, lower back pain, depression, high cholesterol, hypertension, headache/migraine, anxiety, and sleep apnea, were reported by $\geq 20 \%$ of patients at Follow-up. Among patients reporting comorbidities, the mean (standard deviation [SD]) number decreased from 5.1 (2.9) at Baseline to 4.8 (2.6) at Follow-up. There were no statistically significant differences in collected demographic and clinical characteristics observed over time.

"Note that the FIQ-R was administered to patients who were re-diagnosed with fibromyalgia by the physician at Follow-up. 
Table 2. Demographic and clinical characteristics of the sample.

\begin{tabular}{|c|c|c|c|}
\hline Characteristic & $\begin{array}{c}\text { Baseline } \\
(\mathrm{N}=76)\end{array}$ & $\begin{array}{c}\text { Follow-up } \\
(\mathrm{N}=71)\end{array}$ & $P$ value* \\
\hline Age (years), mean (SD) & $50.9(11.3)$ & $53.2(11.9)$ & $\mathrm{N} / \mathrm{A}$ \\
\hline Female, n (\%) & $68(89.5)$ & $63(88.7)$ & $\mathrm{N} / \mathrm{A}$ \\
\hline Non-Hispanic/Latino, n (\%) & $72(94.7)$ & $67(94.4)$ & N/A \\
\hline Employed for pay, n (\%) & $25(32.9)$ & $19(26.8)$ & 0.157 \\
\hline Annual household income, $n(\%)$ & & & 0.335 \\
\hline Under $\$ 20,000$ & $19(25.0)$ & $24(33.8)$ & \\
\hline$\$ 20,000$ to $\$ 44,999$ & $26(34.2)$ & $17(23.9)$ & \\
\hline$\$ 45,000$ to $\$ 64,999$ & $11(14.5)$ & $10(14.1)$ & \\
\hline$\$ 65,000$ to $\$ 89,999$ & $11(14.5)$ & $14(19.7)$ & \\
\hline$\$ 90,000$ to $\$ 124,999$ & $6(7.9)$ & $3(4.2)$ & \\
\hline$\$ 125,000$ or more & $3(3.9)$ & $3(4.2)$ & \\
\hline Health insurance, $\mathrm{n}(\%)$ & $58(76.3)$ & $59(83.1)$ & 0.157 \\
\hline Prescription drug insurance, $\mathrm{n}(\%)$ & $58(76.3)$ & $57(80.3)$ & 0.317 \\
\hline Body mass index, $n(\%)$ & & & 0.172 \\
\hline Underweight $\left(<18.50 \mathrm{~kg} / \mathrm{m}^{2}\right)$ & $3(3.9)$ & $0(0.0)$ & \\
\hline Normal $\left(18.50\right.$ to $\left.24.99 \mathrm{~kg} / \mathrm{m}^{2}\right)$ & $14(18.4)$ & $13(18.3)$ & \\
\hline Overweight (25.00 to $\left.29.99 \mathrm{~kg} / \mathrm{m}^{2}\right)$ & $12(15.8)$ & $17(23.9)$ & \\
\hline Obese $\left(\geq 30 \mathrm{~kg} / \mathrm{m}^{2}\right)$ & $47(61.8)$ & $41(57.7)$ & \\
\hline Time since fibromyalgia diagnosis (years), mean (SD) ${ }^{\dagger}$ & $4.1(7.0)$ & $6.2(7.0)$ & $\mathrm{N} / \mathrm{A}$ \\
\hline Number of comorbid conditions, ${ }^{\ddagger}$ mean (SD) & $5.1(2.9)$ & $4.8(2.6)$ & 0.240 \\
\hline
\end{tabular}

Abbreviations: N/A, not applicable; SD, standard deviation.

* While descriptive statistics are provided for all available patients, $P$ values are only presented for the 71 patients who completed these questions at both time points, where applicable.

${ }^{\dagger} \mathrm{N}=76$ at Baseline and Follow-up. Patients who reported being diagnosed prior to Baseline were reevaluated by the site physician to confirm FM diagnosis. If the prior diagnosis was confirmed, the patient-reported month and year of the initial diagnosis was used. For patients diagnosed for the first time at Baseline $(\mathrm{N}=44)$, time since diagnosis was 0.0 months.

${ }^{\ddagger}$ For those patients with at least one: $\mathrm{N}=73$ at Baseline and $\mathrm{N}=67$ at Follow-up. Patients answered the following question regarding FM-related comorbid conditions: "Please indicate if you have been diagnosed or are currently being treated for any of the following conditions and symptoms." Listed FM-related comorbid conditions included arthritis, depression, irritable bowel syndrome, and sleep apnea, among others.

\section{TREATMENT PATTERNS}

Table 3 presents healthcare resource use among the fibromyalgia patients at both assessments. Prescription medication use for pain in the previous 3 months was similar for both assessments: $59.2 \%$ and $62.0 \%$ of patients, respectively. Fig. (2) presents more detail on the use of prescription medications for pain by class at Baseline and Follow-up. The most commonly reported class of medication for pain in the sample at Follow-up was opioids, with $25.4 \%$ of patients reporting taking weak short-acting opioids, $8.5 \%$ taking strong short-acting opioids, and $7.0 \%$ taking long-acting and extended-release opioids. Opioid use was followed by selective serotonin reuptake inhibitors (SSRIs), tramadol, antiepileptics, and nonsteroidal anti-inflammatory drugs (NSAIDs) use (all $>10 \%$ ) at Follow-up. None of the differences in medication class use for pain were statistically significant; however the classes with the largest (at least a 5 percentage point) change in the rate of use were NSAIDs and muscle relaxants, both of which decreased.

Table 3. Healthcare resource use over the past 3 months.

\begin{tabular}{|l|c|c|c|}
\hline Healthcare Resource Use, $\mathbf{n}(\mathbf{\%})$ & Baseline (N=76) & Follow-up (N=71) & $\boldsymbol{P}$ value \\
\hline HCP visit for pain & $50(65.8)$ & $42(59.2)$ & 0.346 \\
\hline Emergency room visit for pain & $4(5.3)$ & $3(4.2)$ & 1.000 \\
\hline Hospitalized for pain & $3(3.9)$ & $2(2.8)$ & 1.000 \\
\hline Prescribed medication for pain & $45(59.2)$ & $44(62.0)$ & 0.593 \\
\hline Nonprescription medications for pain & $64(84.2)$ & $58(81.7)$ & 0.593 \\
\hline Herbs, vitamins, and other supplements for pain & $25(32.9)$ & $16(22.5)$ & 0.127 \\
\hline Physical treatments for pain & $22(28.9)$ & $27(38.0)$ & 0.088 \\
\hline
\end{tabular}

Abbreviations: HCP, health care provider. 
In addition to prescription medications for pain, most patients reported taking nonprescription medications for pain in the previous 3 months (Baseline: 84.2\%; Follow-up: $81.7 \%$ ). The proportion of patients reporting taking herbs, vitamins, or other pain supplements in the past 3 months dropped from $32.9 \%$ at the Baseline assessment to $22.5 \%$ at the Follow-up assessment. In contrast, there was an increase in the percentage of patients reporting physical treatments for pain over the past 3 months (Baseline: 28.9\%; Follow-up: 38.0\%). The mean (SD) number of health care provider visits over the past 3 months was 3.6 (5.4) and 2.9 (4.4) at Baseline and Follow-up, respectively, and there were few emergency room visits or hospitalizations at either assessment. No changes in pain-related healthcare resource use over time reached statistical significance.

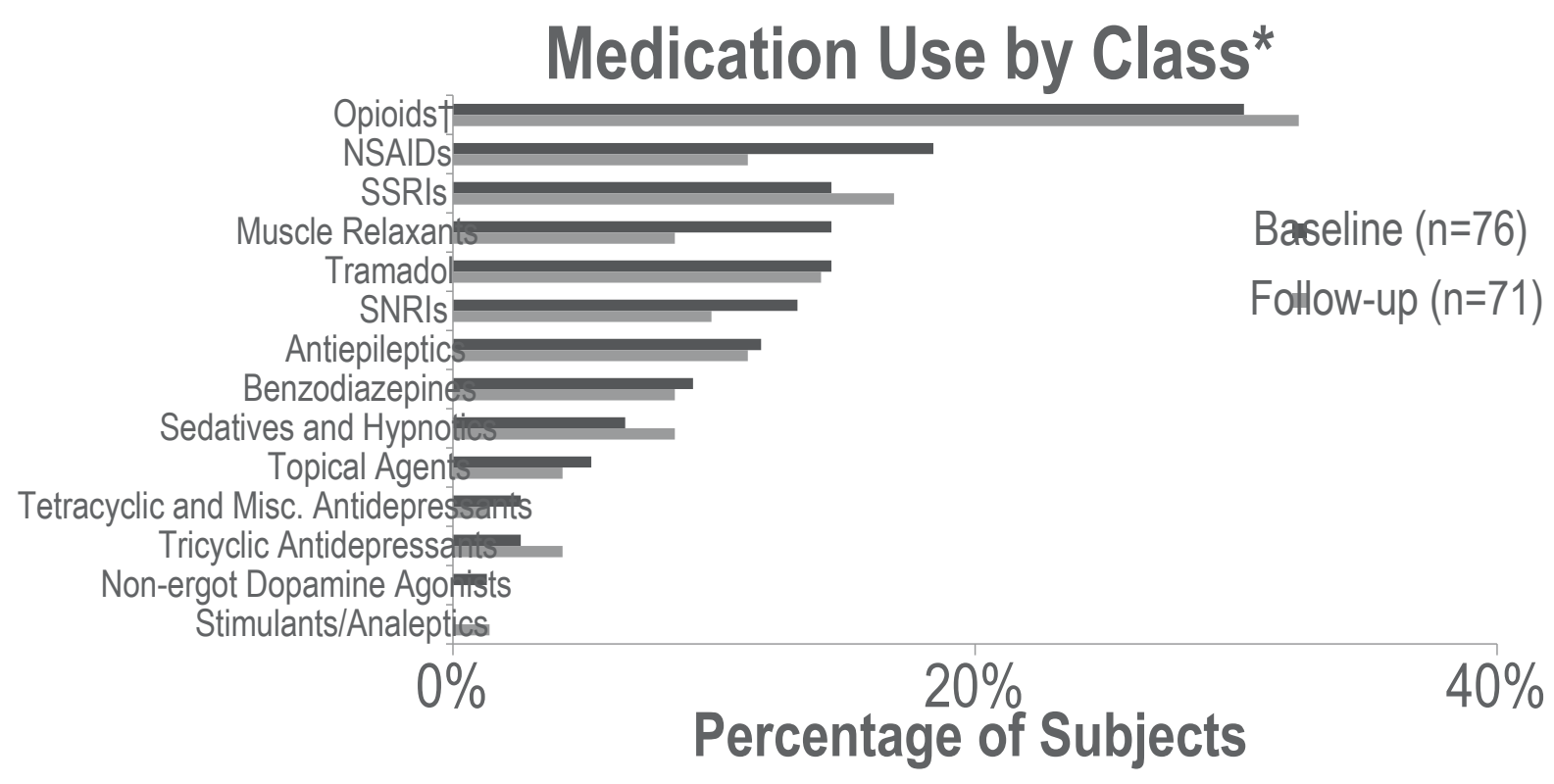

Fig. (2). Medication Use for Pain Over the Past 3 Months by Class at Baseline and Follow-up.

Abbreviations: misc., miscellaneous; NSAID, nonsteroidal anti-inflammatory drug; SNRI, serotonin-norepinephrine reuptake inhibitor; SSRI, selective serotonin reuptake inhibitor.

"No statistically significant differences over time were observed.

‘“Opioids" class includes weak short-acting, strong short-acting, and long-acting and extended-release opioids.

\section{CLINICIAN AND PATIENT-REPORTED OUTCOMES}

The mean (SD) number of tender points at each assessment was 14.1 (3.7) and 13.5 (4.5), respectively. At Followup, $14.5 \%$ of the fibromyalgia patients identified at Baseline no longer screened positive for CWP.

Patients reported mean (SD) average pain severity over the past 7 days as 5.8 (2.0) at Baseline and 5.9 (2.1) at Follow-up; the difference was not statistically significant. No statistically significant difference was observed for mean (SD) BPI-SF Pain Severity Index (5.2 [1.9] to 5.1 [2.2]; Table 4). Only the mean (SD) pain right now item was statistically significantly different between Baseline and Follow-up $(P=0.009$; Table 4). Statistically significant improvement over time was observed for the mean (SD) BPI-SF Pain Interference Index (5.9 [2.4] to 5.3 [2.4]; $P=0.013$; Table 4), as well as for the mood, normal work, sleep, and enjoyment of life items $(P=0.024, P=0.032$, $P=0.006, P=0.021$, respectively; Table 4).

Statistically significant changes over time were observed for the modified ACR 2010 widespread pain index and symptom severity scores, which decreased significantly ( $P=0.038$ and $P=0.007$, respectively; Table 4), as did the mean (SD) total modified ACR 2010 Criteria score: 18.4 (5.6) at Baseline and 16.9 (6.0) at Follow-up (1.6 point decrease; 95\% confidence interval [CI] 0.5 to 2.7; $P=0.004$; Table 4). For those with site confirmation of FM at both assessments, the mean FIQ-R Overall scores only slightly decreased -1.9 points from Baseline to Follow-up $(P=0.268$; Table 4). No statistically significant changes were observed in the FIQ-R function, overall impact, or symptom intensity subscales (Table 4). 
Table 4. Comparison of baseline and follow-up outcomes.

\begin{tabular}{|c|c|c|c|c|}
\hline Patient-reported Outcome, mean (SD) & Baseline ( $N=76)$ & Follow-up $(\mathrm{N}=71)$ & Mean Change (95\% CI) & $P$ value \\
\hline \multicolumn{5}{|l|}{ BPI-SF* } \\
\hline Pain Severity Index & $5.2(1.9)$ & $5.1(2.2)$ & $-0.18(-0.54,0.19)$ & 0.340 \\
\hline Pain at its worst ${ }^{\dagger}$ & $6.7(2.0)$ & $6.4(2.3)$ & $-0.23(-0.72,0.26)$ & 0.356 \\
\hline Pain at its least ${ }^{\dagger}$ & $3.5(2.3)$ & $3.8(2.5)$ & $0.29(-0.18,0.75)$ & 0.221 \\
\hline Average pain & $5.2(1.9)$ & $5.1(2.1)$ & $-0.13(-0.48,0.22)$ & 0.468 \\
\hline Pain right now & $5.5(2.3)$ & $5.0(2.6)$ & $-0.63(-1.10,-0.16)$ & 0.009 \\
\hline Pain Interference Index & $5.9(2.4)$ & $5.3(2.4)$ & $-0.62(-1.11,-0.14)$ & 0.013 \\
\hline General activity & $5.6(2.6)$ & $5.2(2.9)$ & $-0.46(-1.06,0.15)$ & 0.137 \\
\hline Mood & $5.5(2.7)$ & $4.8(2.6)$ & $-0.76(-1.41,-0.10)$ & 0.024 \\
\hline Walking ability & $5.8(3.2)$ & $5.4(3.2)$ & $-0.40(-1.11,0.31)$ & 0.266 \\
\hline Normal work & $6.1(2.7)$ & $5.5(3.0)$ & $-0.66(-1.26,-0.06)$ & 0.032 \\
\hline Relations with others & $4.6(3.1)$ & $4.2(2.9)$ & $-0.49(-1.09,0.12)$ & 0.113 \\
\hline Sleep & $7.0(2.7)$ & $6.1(2.9)$ & $-0.89(-1.51,-0.26)$ & 0.006 \\
\hline Enjoyment of life & $6.4(2.6)$ & $5.7(2.7)$ & $-0.73(-1.34,-0.11)$ & 0.021 \\
\hline \multicolumn{5}{|l|}{ Modified ACR 2010 Criteria } \\
\hline Total Score & $18.4(5.6)$ & $16.9(6.0)$ & $-1.63(-2.74,-0.53)$ & 0.004 \\
\hline Widespread pain index & $10.5(4.4)$ & $9.6(4.8)$ & $-0.92(-1.78,-0.05)$ & 0.038 \\
\hline Symptom severity & $7.8(2.1)$ & $7.2(2.3)$ & $-0.72(-1.24,-0.20)$ & 0.007 \\
\hline \multicolumn{5}{|l|}{ FIQ-R ${ }^{\ddagger}$} \\
\hline Overall Scale & $53.2(19.3)$ & $53.2(20.2)$ & $-1.94(-5.41,1.53)$ & 0.268 \\
\hline Function & $15.0(7.4)$ & $14.7(7.6)$ & $-0.82(-2.10,0.47)$ & 0.209 \\
\hline Overall impact & $9.7(5.9)$ & $10.3(6.1)$ & $-0.12(-1.23,0.98)$ & 0.824 \\
\hline Symptom intensity & $28.5(7.6)$ & $28.2(8.2)$ & $-1.00(-2.73,0.73)$ & 0.252 \\
\hline \multicolumn{5}{|l|}{ MOS-SS } \\
\hline Overall Sleep Problems Index & $58.3(15.7)$ & $52.7(16.5)$ & $-5.27(-8.79,-1.76)$ & 0.004 \\
\hline Sleep disturbance & $56.5(24.1)$ & $50.3(24.4)$ & $-5.60(-10.87,-0.33)$ & 0.038 \\
\hline Snoring & $46.1(34.3)$ & $44.2(32.4)$ & $-2.25(-9.07,4.56)$ & 0.512 \\
\hline Shortness of breath & $26.1(28.1)$ & $21.1(23.2)$ & $-5.92(-12.72,0.89)$ & 0.088 \\
\hline Sleep adequacy & $25.1(20.8)$ & $28.6(22.1)$ & $2.82(-3.62,9.26)$ & 0.386 \\
\hline Somnolence & $54.2(23.7)$ & $48.7(20.6)$ & $-5.73(-9.71,-1.74)$ & 0.006 \\
\hline Sleep quantity & $6.2(1.8)$ & $6.3(1.8)$ & $0.04(-0.46,0.55)$ & 0.868 \\
\hline \multicolumn{5}{|l|}{ WPAI } \\
\hline Activity Impairment (\%) & $58.4(24.8)$ & $59.4(27.0)$ & $0.56(-4.37,5.49)$ & 0.820 \\
\hline Overall Work Impairment $(\%)^{\S}$ & $39.4(24.9)$ & $37.9(20.9)$ & $1.93(-8.22,12.08)$ & 0.692 \\
\hline Absenteeism & $6.5(11.9)$ & $4.9(16.4)$ & $-0.91(-9.39,7.58)$ & 0.824 \\
\hline Presenteeism & $36.4(22.9)$ & $36.8(19.5)$ & $4.12(-4.02,12.26)$ & 0.300 \\
\hline \multicolumn{5}{|l|}{ SF-12 } \\
\hline Physical Component Summary & $32.8(10.8)$ & $34.1(11.0)$ & $1.53(-0.23,3.30)$ & 0.088 \\
\hline Mental Component Summary & $41.9(10.5)$ & $42.4(10.9)$ & $1.13(-1.15,3.41)$ & 0.328 \\
\hline Physical functioning & $33.6(31.8)$ & $36.3(31.8)$ & $2.82(-2.80,8.44)$ & 0.321 \\
\hline Role physical & $36.2(26.4)$ & $41.2(27.8)$ & $6.51(1.20,11.83)$ & 0.017 \\
\hline Bodily pain & $40.5(24.5)$ & $43.3(26.4)$ & $3.52(-1.41,8.45)$ & 0.159 \\
\hline General health & $42.8(26.7)$ & $44.9(24.6)$ & $3.03(-0.84,6.89)$ & 0.123 \\
\hline Vitality & $23.0(23.0)$ & $24.3(22.0)$ & $2.82(-2.53,8.16)$ & 0.297 \\
\hline Social functioning & $51.0(27.8)$ & $53.5(27.5)$ & $4.23(-2.48,10.93)$ & 0.213 \\
\hline Role emotional & $63.2(26.0)$ & $63.6(26.4)$ & $1.76(-4.21,7.73)$ & 0.558 \\
\hline Mental health & $52.0(20.3)$ & $54.4(23.4)$ & $3.17(-2.05,8.38)$ & 0.230 \\
\hline
\end{tabular}

Abbreviations: BPI-SF, Brief Pain Inventory-Short Form; EQ-5D, EuroQol 5 dimensions, 3 levels; MOS-SS, Medical Outcomes Study-Sleep Scale; pt, point; SD, standard deviation; SF-12, 12-item Short-Form Health Survey; WPAI, Work Productivity and Activity Impairment scale.

"A total of 76 fibromyalgia patients attended the site visit at Follow-up, but 5 patients did not complete the patient questionnaire following the site visit; 1 patient did not report pain at Follow-up and, therefore, did not complete the BPI-SF.

In the past 24 hours.

${ }^{\ddagger}$ The FIQ-R was administered only to subjects who had fibromyalgia: Baseline n=74; Follow-up n=59. 
${ }^{\S}$ Among those employed for pay, $\mathrm{n}=25$ at Baseline and $\mathrm{n}=19$ at Follow-up.

The change in mean (SD) MOS-SS Overall Sleep Problems Index was statistically significant: 58.3 (15.7) at Baseline to 52.7 (16.5) at Follow-up (5.3 point decrease; $95 \%$ CI 1.8 to $8.8 ; P=0.004$; Table 4) and, while numerical improvements were generally seen in each of the dimensions, only the improvements in sleep disturbance and somnolence scores were statistically significant $(P=0.038$ and $P=0.006$, respectively; Table 4).

There were no statistically significant differences in WPAI Activity Impairment over time (mean [SD]: 58.4\% [24.8\%] to 59.4\% [27.0\%]; $P=0.820$; Table 4). Similarly, among those employed for pay ( $\mathrm{n}=25$ at Baseline and $\mathrm{n}=19$ at Follow-up), there were no statistically significant differences in WPAI Overall Work Impairment (mean [SD]: 39.4\% [24.9\%] to 37.9\% [20.9\%]; $P=0.692$ ), nor in the absenteeism and presenteeism subscales (Table 4).

No statistically significant differences were observed for the mean (SD) EQ-5D health state utility $(0.63$ [0.20] to 0.66 [0.19]), or for the SF-12 Physical Component Summary (32.8 [10.8] to 34.1 [11.0]) and Mental Component Summary (41.9 [10.5] to 42.4 [10.9]) scores. Among the SF-12 domains, only role physical improved significantly over time $(P=0.017$; Table 4).

\section{PAIN IMPROVEMENT SUBGROUP ANALYSIS}

Of the 76 fibromyalgia patients, $11(14.5 \%)$ achieved a $\geq 2.0$-point improvement between Baseline and Follow-up in average pain severity over the past 7 days. Among the group with $\geq 2.0$ point improvement, the mean number of tender points decreased from Baseline (14.0 [4.00]) to Follow-up (12.1 [4.48]).

At Follow-up, those who achieved $\mathrm{a} \geq 2$.0-point improvement in pain had fewer mean (SD) tender points (12.1 [4.5]) compared to those who did not have this level of pain improvement (13.7 [4.5]). Similarly, statistically significant improvements in BPI-SF Pain Severity Index (-2.43 points; 95\% CI -3.26 to $-1.61 ; P<0.001)$ and BPI-SF Pain Interference Index (-3.35 points; $95 \%$ CI -4.89 to $-1.81 ; P=0.001)$ were observed among those who achieved a $\geq 2.0$ point improvement in pain; statistically significant improvements in these measures were not observed among those who did not have this level of pain improvement (Table 5).

Table 5. Subgroup analysis-comparison of baseline and follow-up outcomes among pain improvement subgroup* and remaining sample.

\begin{tabular}{|c|c|c|c|c|}
\hline Patient-reported Outcome, mean (SD) & Baseline & Follow-up & Mean Change (95\% CI) & $P$ value \\
\hline \multicolumn{5}{|l|}{ BPI-SF Pain Severity Index ${ }^{\dagger}$} \\
\hline$\geq 2$ pt improvement & $5.6(1.3)$ & $3.1(1.8)$ & $-2.43(-3.26,-1.61)$ & $<0.001$ \\
\hline$<2$ pt improvement & $5.2(2.0)$ & $5.5(2.1)$ & $0.25(-0.06,0.55)$ & 0.111 \\
\hline \multicolumn{5}{|l|}{ BPI-SF Pain Interference Index ${ }^{\dagger}$} \\
\hline$\geq 2$ pt improvement & $6.8(1.7)$ & $3.4(2.4)$ & $-3.35(-4.89,-1.81)$ & 0.001 \\
\hline$<2$ pt improvement & $5.7(2.5)$ & $5.6(2.3)$ & $-0.12(-0.52,0.29)$ & 0.568 \\
\hline \multicolumn{5}{|l|}{ WPAI Activity Impairment ${ }^{\dagger}$} \\
\hline$\geq 2 \mathrm{pt} \mathrm{improvement}$ & $59.1(25.9)$ & $50.0(23.2)$ & $-9.09(-31.86,13.68)$ & 0.395 \\
\hline$<2$ pt improvement & $58.3(24.9)$ & $61.2(27.5)$ & $2.33(-2.14,6.80)$ & 0.301 \\
\hline \multicolumn{5}{|l|}{ MOS-SS Overall Sleep Problems Index ${ }^{\dagger}$} \\
\hline$\geq 2$ pt improvement & $62.4(13.9)$ & $51.0(17.5)$ & $-11.41(-23.49,0.66)$ & 0.061 \\
\hline$<2$ pt improvement & $57.6(16.0)$ & $53.0(16.4)$ & $-4.15(-7.78,-0.51)$ & 0.026 \\
\hline \multicolumn{5}{|l|}{ EQ-5D } \\
\hline$\geq 2 \mathrm{pt} \mathrm{improvement}$ & $0.59(0.21)$ & $0.68(0.20)$ & $0.09(-0.05,0.24)$ & 0.189 \\
\hline$<2$ pt improvement & $0.64(0.19)$ & $0.65(0.19)$ & $0.02(-0.03,0.06)$ & 0.518 \\
\hline \multicolumn{5}{|l|}{ SF-12 Physical Component Summary ${ }^{\dagger}$} \\
\hline$\geq 2 \mathrm{pt}$ improvement & $37.0(8.3)$ & $38.6(8.0)$ & $1.67(-3.75,7.09)$ & 0.508 \\
\hline$<2$ pt improvement & $32.1(11.1)$ & $33.3(11.3)$ & $1.51(-0.41,3.43)$ & 0.121 \\
\hline
\end{tabular}

Abbreviations: BPI-SF, Brief Pain Inventory-Short Form; EQ-5D, EuroQol 5 dimensions, 3 levels; MOS-SS, Medical Outcomes Study-Sleep Scale; pt, point; SD, standard deviation; SF-12, 12-item Short-Form Health Survey; WPAI, Work Productivity and Activity Impairment scale.

"These patients experienced clinically meaningful (i.e., at least 2.0 points) improvement in average pain severity over the past 7 days between Baseline and Follow-up assessments.

${ }^{\dagger}$ A total of 76 fibromyalgia patients ( 11 with $\geq 2$ point improvement, 65 with $<2$ point improvement) attended the site visit at Follow-up, but 5 patients in the subgroup with $<2$ point improvement did not complete the patient questionnaire following the site visit. 
Though not statistically significant, the mean changes on the WPAI Activity Impairment (-9.09 points; $95 \%$ CI: -31.86 to $13.68 ; P=0.395)$, the MOS-SS Overall Sleep Problems Index ( -11.41 points; $95 \%$ CI -23.49 to $0.66 ; P=0.061)$, SF-12 Physical Component Summary (1.67 points; $95 \%$ CI -3.75 to $7.09 ; P=0.508$ ), and the EQ-5D health state utility ( 0.09 points; $95 \%$ CI -0.05 to $0.24 ; P=0.189)$ were all greatest for those who had a $\geq 2.0$-point improvement in pain over time (Table 5).

Prescription medication use for pain was lower for the patients who achieved a $\geq 2.0$-point improvement (Baseline: $36.4 \%$ vs. Follow-up: $45.5 \% ; P=0.564$ ) compared to those who did not (Baseline: 63.1\% vs. Follow-up: 65.0\%; $P=0.763)$.

\section{DISCUSSION}

This prospective observational study used online data collection tools for PROs, combined with an in-person physician assessment, to evaluate changes in pain and clinical outcomes, sleep, pain interference with function, and health status among fibromyalgia patients over time.

The study sample was geographically diverse yet similar across baseline demographic and clinical characteristics to other fibromyalgia samples in the published literature [2, 6, 43, 44]. The study also included in-person evaluation at the same site at Baseline and Follow-up and administration of the same PRO measures at both time points, which allowed for an assessment of changes over time. The sample included fibromyalgia patients diagnosed, on average, 4.1 years before the Baseline visit. We observed no statistically significant differences among fibromyalgia patients between Baseline and Follow-up in terms of employment status, household income, health insurance, prescription coverage, BMI, and number of comorbidities.

Many patients in the sample received medical care and treatment for fibromyalgia, as reflected in the high levels of prescription and nonprescription pain medications, physical treatments, and visits to healthcare providers reported by patients. It is important to consider the frequently reported classes of prescription medications in this fibromyalgia sample in the context of Food and Drug Administration-approved medications for the treatment of fibromyalgia (pregabalin, duloxetine, milnacipran) and published treatment guidelines, which also include gabapentin, amitriptyline, SSRIs, SNRIs, and tramadol. Guidelines generally do not recommend opioids, especially strong opioids, for fibromyalgia [45 - 49]. However, in this study, opioids were the most widely utilized medication, and at Follow-up, increases in the percentage of patients prescribed weak short-acting opioids and long-acting and extended-release opioids were observed along with increases in the use of SSRIs. NSAIDs were also widely used at both time points.

Overall mean scores for general and disease-specific PROs reflect continued high levels of disease burden in this sample. For example, the SF-12 mental and physical component summary scores and EQ-5D at both time points were well below the US general population norms of 49.5, 49.7 [50], and 0.87 [51], respectively. Patients reported similar levels of pain (BPI-SF Pain Severity Index) and tender points, on average, at Baseline and Follow-up. Productivity impairment likewise remained high at both time points.

However, scores on several PROs suggest variability in terms of changes from Baseline to Follow-up. Patients reported improvement in fibromyalgia symptoms (modified ACR 2010 Criteria) and pain interference with function (BPI-SF Pain Interference Index), and these differences were statistically significant. Additionally, statistically significant improvements in sleep (MOS-SS Overall Sleep Problems) were observed. These results contrast with the findings of a previous 7-year US study of fibromyalgia patients in which functional disability worsened and pain, health status, fatigue, and sleep disturbance remained unchanged [24]. It is possible that patients in our sample over or underestimated their functional abilities over time. In future studies, longitudinal performance testing may be helpful to understand these phenomena better.

Our pain improvement subgroup analysis showed that a minority of patients (14.5\%) experienced $\geq 2$ point improvement in pain severity between the two time points. Physicians reported improvements in the number of tender points in these patients and the patients reported improvements in health status, sleep, and pain interference with function; whereas those who did not report this level of pain improvement, representing the majority of the sample, generally did not. Of note, Baseline scores for pain severity, pain interference with function, sleep, and health status were worse for the pain improvement subgroup than those who did not experience $\geq 2$ point improvement in pain.

Taken together, these findings support the conclusions of previous research, which suggests that while fibromyalgia is a chronic illness, there may be waxing and waning of symptoms, as well as a portion of patients who experience improvements following diagnosis and treatment. In one previous study, $66 \%$ of fibromyalgia patients in rheumatology 
clinics reported their symptoms were a little to a lot better at the 10-year interview than when they were first diagnosed; those patient-reported improvements were correlated with younger age and shorter duration of fibromyalgia symptoms at diagnosis [18]. In a more recent study, $47 \%$ of outpatients with fibromyalgia reported moderate to marked improvement over 3 years [52]. Some published research suggests that outcomes are better for individuals in the community compared to individuals in rheumatology clinics [53, 54]. Improvements also may be related to treatment, both pharmacologic and nonpharmacologic.

\section{STRENGTHS AND LIMITATIONS}

Strengths of this study include the collection of comprehensive real world data on the burden of fibromyalgia directly from patients recruited from the general population (i.e., not a convenience sample recruited from the clinic setting) as well as the inclusion of in-person physician evaluation to determine fibromyalgia diagnosis at Baseline and Follow-up. However, it is also important to acknowledge limitations of the study to aid in the interpretation of results.

Seventy-six (37\%) of the 205 eligible fibromyalgia patients who participated at Baseline also completed the Followup assessment. Unfortunately, data from individuals lost to follow-up, including the reason(s) for not participating in the Follow-up assessment, are limited. The similarity of our sample to other fibromyalgia samples helps to address this limitation.

At both Baseline and Follow-up there was a potential for recall bias, which could lead to over- or underestimation of patient-reported healthcare resource use and other variables, such as medications prescribed or number of office visits. Further, it is important to acknowledge potential for regression to the mean bias, whereby baseline scores may be negatively correlated with change scores, in a prospective assessment like this one [55]. We also note that mean WPAI Overall Work Impairment scores were from the relatively small sample employed for pay, which may have limited the ability to detect change over time; however, all subjects regardless of employment status completed the WPAI Activity Impairment scale.

Finally, given the observational nature of the study and the gap in the collected healthcare resource use data between assessments, we were unable to assess the impact of treatment(s) on outcomes. Future research to better understand the impact of both pharmacologic and nonpharmacologic treatments on real-world outcomes is warranted.

\section{CONCLUSION}

Fibromyalgia patients continued to report high levels of disease burden, on average, in terms of pain and health status approximately 2 years after the Baseline assessment. There was variability among patients in clinician and patient-reported outcomes, with few significant differences observed over time. These data suggest some improvement over time in function and sleep, particularly among the minority of patients who reported greater improvement in pain.

\section{DISCLOSURES}

This study was sponsored by Pfizer Inc. Margarita Udall, Elizabeth T. Masters, Joseph C. Cappelleri, Andrew Clair, and Markay Hopps are employees of Pfizer Inc. Caroline Schaefer, Rachael Mann, Shoshana Daniel, and Heather McElroy are employees of Covance Market Access Services Inc., which was paid by Pfizer Inc for study design, execution, analysis, and manuscript development. Edgar Adams was an employee of Covance Market Access Services Inc. at the time of the study and manuscript development, and is now retired. Roland Staud, Philip Mease, and Stuart Silverman were investigators for the study and were not financially compensated for collaborative efforts on publication-related activities.

\section{ACKNOWLEDGEMENTS}

The authors would like to acknowledge Arthi B. Chandran, Annlouise Assaf, and Gergana Zlateva for their contributions to the study design, Rebecca Baik for her programming support, Dr. Michael McNett for contributions to the study execution and interpretation of findings, and the study investigators for their contributions to the study execution.

\section{REFERENCES}

[1] Wolfe F, Ross K, Anderson J, Russell IJ, Hebert L. The prevalence and characteristics of fibromyalgia in the general population. Arthritis Rheum 1995; 38(1): 19-28. [http://dx.doi.org/10.1002/art.1780380104] [PMID: 7818567] 
[2] Schaefer C, Chandran A, Hufstader M, et al. The comparative burden of mild, moderate and severe fibromyalgia: results from a crosssectional survey in the United States. Health Qual Life Outcomes 2011; 9: 71-83. [http://dx.doi.org/10.1186/1477-7525-9-71] [PMID: 21859448]

[3] Bennett RM, Jones J, Turk DC, Russell IJ, Matallana L. An internet survey of 2,596 people with fibromyalgia. BMC Musculoskelet Disord 2007; 8: 27-37. [http://dx.doi.org/10.1186/1471-2474-8-27] [PMID: 17349056]

[4] Prescott E, Kjøller M, Jacobsen S, Bülow PM, Danneskiold-Samsøe B, Kamper-Jørgensen F. Fibromyalgia in the adult Danish population: I. A prevalence study. Scand J Rheumatol 1993; 22(5): 233-7. [http://dx.doi.org/10.3109/03009749309095129] [PMID: 8235493]

[5] Forseth KO, Gran JT. The prevalence of fibromyalgia among women aged 2049 years in Arendal, Norway. Scand J Rheumatol 1992; 21(2): $74-8$. [http://dx.doi.org/10.3109/03009749209095071] [PMID: 1570493]

[6] Vincent A, Lahr BD, Wolfe F, et al. Prevalence of fibromyalgia: a population-based study in Olmsted County, Minnesota, utilizing the Rochester Epidemiology Project. Arthritis Care Res (Hoboken) 2013; 65(5): 786-92. [http://dx.doi.org/10.1002/acr.21896] [PMID: 23203795]

[7] Hoffman DL, Dukes EM. The health status burden of people with fibromyalgia: a review of studies that assessed health status with the SF-36 or the SF-12. Int J Clin Pract 2008; 62(1): 115-26. [http://dx.doi.org/10.1111/j.1742-1241.2007.01638.x] [PMID: 18039330]

[8] Salaffi F, Sarzi-Puttini P, Girolimetti R, Atzeni F, Gasparini S, Grassi W. Health-related quality of life in fibromyalgia patients: a comparison with rheumatoid arthritis patients and the general population using the SF-36 health survey. Clin Exp Rheumatol 2009; 27(5)(Suppl. 56): S67-74.

[PMID: 20074443]

[9] Wolfe F, Michaud K, Li T, Katz RS. EQ-5D and SF-36 quality of life measures in systemic lupus erythematosus: comparisons with rheumatoid arthritis, noninflammatory rheumatic disorders, and fibromyalgia. J Rheumatol 2010; 37(2): 296-304. [http://dx.doi.org/10.3899/jrheum.090778] [PMID: 20032098]

[10] Luo X, Cappelleri J, Chandran A. The burden of fibromyalgia: assessment of health status using the EuroQol (EQ-5D) in patients with fibromyalgia relative to other chronic conditions. Health Outcomes Res Med 2011; 2: e203-14. [http://dx.doi.org/10.1016/j.ehrm.2011.08.002]

[11] Jones J, Rutledge DN, Jones KD, Matallana L, Rooks DS. Self-assessed physical function levels of women with fibromyalgia: a national survey. Womens Health Issues 2008; 18(5): 406-12. [http://dx.doi.org/10.1016/j.whi.2008.04.005] [PMID: 18723374]

[12] Robinson RL, Kroenke K, Mease P, et al. Burden of illness and treatment patterns for patients with fibromyalgia. Pain Med 2012; 13(10): 1366-76. [http://dx.doi.org/10.1111/j.1526-4637.2012.01475.x] [PMID: 22958298]

[13] Chandran A, Schaefer C, Ryan K, Baik R, McNett M, Zlateva G. The comparative economic burden of mild, moderate, and severe fibromyalgia: results from a retrospective chart review and cross-sectional survey of working-age U.S. adults. J Manag Care Pharm 2012; 18(6): 415-26.

[http://dx.doi.org/10.18553/jmcp.2012.18.6.415] [PMID: 22839682]

[14] White LA, Robinson RL, Yu AP, et al. Comparison of health care use and costs in newly diagnosed and established patients with fibromyalgia. J Pain 2009; 10(9): 976-83. [http://dx.doi.org/10.1016/j.jpain.2009.03.012] [PMID: 19556168]

[15] Berger A, Dukes E, Martin S, Edelsberg J, Oster G. Characteristics and healthcare costs of patients with fibromyalgia syndrome. Int J Clin Pract 2007; 61(9): 1498-508.

[http://dx.doi.org/10.1111/j.1742-1241.2007.01480.x] [PMID: 17655684]

[16] White LA, Birnbaum HG, Kaltenboeck A, Tang J, Mallett D, Robinson RL. Employees with fibromyalgia: medical comorbidity, healthcare costs, and work loss. J Occup Environ Med 2008; 50(1): 13-24. [http://dx.doi.org/10.1097/JOM.0b013e31815cff4b] [PMID: 18188077]

[17] Walitt B, Fitzcharles MA, Hassett AL, Katz RS, Häuser W, Wolfe F. The longitudinal outcome of fibromyalgia: a study of 1555 patients. J Rheumatol 2011; 38(10): 2238-46. [http://dx.doi.org/10.3899/jrheum.110026] [PMID: 21765102]

[18] Kennedy M, Felson DT. A prospective long-term study of fibromyalgia syndrome. Arthritis Rheum 1996; $39(4): 682-5$. [http://dx.doi.org/10.1002/art.1780390422] [PMID: 8630121]

[19] Forseth KO, Førre O, Gran JT. A 5.5 year prospective study of self-reported musculoskeletal pain and of fibromyalgia in a female population: significance and natural history. Clin Rheumatol 1999; 18(2): 114-21. [http://dx.doi.org/10.1007/s100670050067] [PMID: 10357115]

[20] Ledingham J, Doherty S, Doherty M. Primary fibromyalgia syndromean outcome study. Br J Rheumatol 1993; 32(2): 139-42. [http://dx.doi.org/10.1093/rheumatology/32.2.139] [PMID: 8428227] 
[21] Bengtsson A, Backman E, Lindblom B, Skogh T. Long-term follow up of fibromyalgia patients: clinical symptoms, muscular function, laboratory tests-an eight year comparison study. J Musculoskeletal Pain 1994; 2(2): 67-80. [http://dx.doi.org/10.1300/J094v02n02_06]

[22] Granges G, Zilko P, Littlejohn GO. Fibromyalgia syndrome: assessment of the severity of the condition 2 years after diagnosis. J Rheumatol 1994; 21(3): 523-9. [PMID: 8006897]

[23] White KP, Harth M. Classification, epidemiology, and natural history of fibromyalgia. Curr Pain Headache Rep 2001; 5(4): 320-9. [http://dx.doi.org/10.1007/s11916-001-0021-2] [PMID: 11403735]

[24] Wolfe F, Anderson J, Harkness D, et al. Health status and disease severity in fibromyalgia: results of a six-center longitudinal study. Arthritis Rheum 1997; 40(9): 1571-9.

[http://dx.doi.org/10.1002/art.1780400905] [PMID: 9324010]

[25] Adams EH, McElroy HJ, Udall M, et al. Progression of fibromyalgia: results from a 2-year observational fibromyalgia and chronic pain study in the US. J Pain Res 2016; 9: 325-36. [PMID: 27330325]

[26] Schaefer C, Mann R, Masters ET, et al. The comparative burden of chronic widespread pain and fibromyalgia in the United States. Pain Pract 2016; 16(5): 565-79. [http://dx.doi.org/10.1111/papr.12302] [PMID: 25980433]

[27] Toluna Database. C 2014 Toluna Group Ltd. [accessed 2014 January 24]. Available from: https://us.toluna.com/.

[28] White KP, Harth M, Speechley M, Ostbye T. Testing an instrument to screen for fibromyalgia syndrome in general population studies: the London Fibromyalgia Epidemiology Study Screening Questionnaire. J Rheumatol 1999; 26(4): 880-4. [PMID: 10229410]

[29] Sinclair J, Starz TW, Turk D. The Manual Tender Point Survey. Pittsburgh, PA: University of Pittsburgh Medical Center, Center for Continuing Education in the Health Sciences 1997

[30] Vargas A, Vargas A, Hernández-Paz R, et al. Sphygmomanometry-evoked allodyniaa simple bedside test indicative of fibromyalgia: a multicenter developmental study. J Clin Rheumatol 2006; 12(6): 272-4. [http://dx.doi.org/10.1097/01.rhu.0000249770.86652.3b] [PMID: 17149055]

[31] Rabin R, de Charro F. EQ-5D: a measure of health status from the EuroQol Group. Ann Med 2001; $33(5)$ : $337-43$. [http://dx.doi.org/10.3109/07853890109002087] [PMID: 11491192]

[32] Cleeland C. The Brief Pain Inventory User Guide [accessed 2011 July 05]. Available from: http://www.mdanderson.org/ education-andresearch/departments-programs-and-labs/departments-and-divisions/symptom-research/symptom-assessment-tools/BPI_UserGuide.pdf

[33] Wolfe F, Clauw DJ, Fitzcharles MA, et al. Fibromyalgia criteria and severity scales for clinical and epidemiological studies: a modification of the ACR Preliminary Diagnostic Criteria for Fibromyalgia. J Rheumatol 2011; 38(6): 1113-22. [http://dx.doi.org/10.3899/jrheum.100594] [PMID: 21285161]

[34] Bennett RM, Friend R, Jones KD, Ward R, Han BK, Ross RL. The Revised Fibromyalgia Impact Questionnaire (FIQR): validation and psychometric properties. Arthritis Res Ther 2009; 11(4): R120. [http://dx.doi.org/10.1186/ar2783] [PMID: 19664287]

[35] Hays R, Stewartm A. Sleep Measures Measuring Functioning and Well-being: the Medical Outcomes Study Approach 1992.

[36] Ware J Jr, Kosinski M, Keller SD. A 12-Item Short-Form Health Survey: construction of scales and preliminary tests of reliability and validity. Med Care 1996; 34(3): 220-33. [http://dx.doi.org/10.1097/00005650-199603000-00003] [PMID: 8628042]

[37] Reilly MC, Zbrozek AS, Dukes EM. The validity and reproducibility of a work productivity and activity impairment instrument. Pharmacoeconomics 1993; 4(5): 353-65.

[http://dx.doi.org/10.2165/00019053-199304050-00006] [PMID: 10146874]

[38] Stuart A. A test for homogeneity of the marginal distributions in a two-way classification. Biometrika 1995; 42: 412-6. [http://dx.doi.org/10.1093/biomet/42.3-4.412]

[39] Dworkin RH, Turk DC, Wyrwich KW, et al. Interpreting the clinical importance of treatment outcomes in chronic pain clinical trials: IMMPACT recommendations. J Pain 2008; 9(2): 105-21.

[http://dx.doi.org/10.1016/j.jpain.2007.09.005] [PMID: 18055266]

[40] Freeman R, Emir B, Parsons B. Predictors of placebo response in peripheral neuropathic pain: insights from pregabalin clinical trials. J Pain Res 2015; 8: 257-68. [PMID: 26082659]

[41] Farrar JT, Young JP Jr, LaMoreaux L, Werth JL, Poole RM. Clinical importance of changes in chronic pain intensity measured on an 11-point numerical pain rating scale. Pain 2001; 94(2): 149-58. [http://dx.doi.org/10.1016/S0304-3959(01)00349-9] [PMID: 11690728]

[42] Obesity: preventing and managing the global epidemic. Report of a WHO consultation. World Health Organ Tech Rep Ser 2000; 894: i-xii, $1-253$. 
[PMID: 11234459]

[43] Wolfe F, Goldenberg DL, Walitt BT, Häuser W, Eds. The Polysymptomatic Distress Scale as a measure of disease and practice severity in fibromyalgia. American College of Rheumatology Annual Meeting; October 25-30; San Diego, CA. 2013.

[44] Kim CH, Luedtke CA, Vincent A, Thompson JM, Oh TH. Association of body mass index with symptom severity and quality of life in patients with fibromyalgia. Arthritis Care Res (Hoboken) 2012; 64(2): 222-8. [http://dx.doi.org/10.1002/acr.20653] [PMID: 21972124]

[45] Arnold LM, Clauw DJ, Dunegan LJ, Turk DC. A framework for fibromyalgia management for primary care providers. Mayo Clin Proc 2012; 87(5): 488-96.

[http://dx.doi.org/10.1016/j.mayocp.2012.02.010] [PMID: 22560527]

[46] Carville SF, Arendt-Nielsen L, Bliddal H, et al. EULAR evidence-based recommendations for the management of fibromyalgia syndrome. Ann Rheum Dis 2008; 67(4): 536-41. [http://dx.doi.org/10.1136/ard.2007.071522] [PMID: 17644548]

[47] Fitzcharles MA, Ste-Marie PA, Goldenberg DL, et al. 2012 Canadian Guidelines for the diagnosis and management of fibromyalgia syndrome: executive summary. Pain Res Manag 2013; 18(3): 119-26. [http://dx.doi.org/10.1155/2013/918216] [PMID: 23748251]

[48] Ablin JN, Amital H, Ehrenfeld M, et al. Guidelines for the diagnosis and treatment of the fibromyalgia syndrome. Harefuah 2013; 152(12): $742-7,51,50$.

[49] Dreher T, Häuser W, Schiltenwolf M. [Fibromyalgia syndrome - updated s3 guidelines]. Z Orthop Unfall 2013; 151(6): 603-9. [PMID: 24347415]

[50] Ware J, Kosinski M, Turner-Bowker D, Sundaram M, Gandek B, Maruish M. User's Manual for the SF-12v2 Health Survey. $2^{\text {nd }}$. QualityMetric, edi 2009.

[51] Luo N, Johnson JA, Shaw JW, Feeny D, Coons SJ. Self-reported health status of the general adult U.S. population as assessed by the EQ-5D and Health Utilities Index. Med Care 2005; 43(11): 1078-86. [http://dx.doi.org/10.1097/01.mlr.0000182493.57090.c1] [PMID: 16224300]

[52] Fitzcharles MA, Da Costa D, Pöyhiä R. A study of standard care in fibromyalgia syndrome: a favorable outcome. J Rheumatol 2003; 30(1): 154-9.

[PMID: 12508406]

[53] MacFarlane GJ, Thomas E, Papageorgiou AC, Schollum J, Croft PR, Silman AJ. The natural history of chronic pain in the community: a better prognosis than in the clinic? J Rheumatol 1996; 23(9): 1617-20. [PMID: 8877934]

[54] Goldenberg DL. Fibromyalgia syndrome a decade later: what have we learned? Arch Intern Med 1999; 159(8): 777-85. [http://dx.doi.org/10.1001/archinte.159.8.777] [PMID: 10219923]

[55] Barnett AG, van der Pols JC, Dobson AJ. Regression to the mean: what it is and how to deal with it. Int J Epidemiol 2005; 34(1): 215-20. [http://dx.doi.org/10.1093/ije/dyh299] [PMID: 15333621]

(C) Schaefer et al.; Licensee Bentham Open

This is an open access article licensed under the terms of the Creative Commons Attribution-Non-Commercial 4.0 International Public License (CC BY-NC 4.0) (https://creativecommons.org/licenses/by-nc/4.0/legalcode), which permits unrestricted, non-commercial use, distribution and reproduction in any medium, provided the work is properly cited. 